\title{
Efeitos do Envelhecimento Térmico na Microestrutura e na Resistência à Corrosão do Metal de Solda de Aço AISI 317L
}

\author{
(Effects of Thermal Aging on Microstructure and Corrosion Resistance of AISI 317L Steel Weld Metal)
}

\author{
Humberto N. Farneze', Sérgio S. M. Tavares², Juan M. Pardal ${ }^{3}$, Guttemberg C. de Souza ${ }^{4}$ \\ ${ }^{1}$ CEFET/RJ, UnED Itaguai, Itaguai, RJ, Brasil, humbertofarneze@globo.com \\ 2,3,4UFF, PGMEC,Niterói, RJ, Brasil,ssmtavares@terra.com.br,juanpardal@vm.uff.br, guttemberg.souza@utc.com.br
}

\begin{abstract}
Resumo
Visando uma análise da evolução microestrutural e da resistência à corrosão do metal de solda em aço AISI 317L, obtido pelo processo $G T A W$, realizou-se a avaliação do efeito de exposições prolongadas a $550^{\circ} \mathrm{C}$, através de tratamentos térmicos por $200 \mathrm{~h}$, $300 \mathrm{~h}$ e $400 \mathrm{~h}$. Após cada tratamento foi efetuada uma caracterização microestrutural por microscopia eletrônica de varredura (MEV). Em seguida, foram realizados testes de polarização eletroquímica de reativação cíclica (PERC), para avaliar o grau de sensitização das amostras. Os resultados obtidos indicaram que o aumento do tempo de exposição promoveu a formação progressiva de fases intermetálicas, comprometendo a resistência à corrosão intergranular do metal de solda. Tais resultados contribuirão para uma melhor previsão do comportamento de soldas em aço AISI $317 \mathrm{~L}$, durante a operação dos equipamentos da indústria de processo.
\end{abstract}

Palavras-Chave: Aço inoxidável austenítico AISI 317L. Processo GTAW. PERC. Fases deletérias.

Abstract: Aiming at an analysis of the microstructural evolution and corrosion resistance of the weld metal in steel AISI 317L, obtained by GTAW process, conducted to evaluate the effect of prolonged exposure at $550^{\circ} \mathrm{C}$ by thermal treatment for $200 \mathrm{~h}, 300 \mathrm{~h}$ and $400 \mathrm{~h}$. After each treatment microstructural characterization was performed by scanning electron microscopy (SEM). Double loop electrochemical polarization reactivation tests (DL-EPR) were performed to evaluate the degree of sensitization of the samples. The results indicated that increasing the exposure time at $550^{\circ} \mathrm{C}$ promoted the progressive formation of intermetallic phases, which caused corrosion decay of the weld metal. These results contribute to a better prediction of the behavior of AISI $317 \mathrm{~L}$ welded joins during operation of the process equipment industry.

Key-words: AISI $317 L$ austenitic stainless steel. GTAW process. DL-EPR. Deleterious phases.

\section{Introdução}

Os aços inoxidáveis austeníticos formam o maior grupo de aços inoxidáveis em uso, representando cerca de 65 a 70\% do total produzido. Dentre as propriedades que se destacam nestes tipos de aços, está à boa resistência mecânica e à corrosão a temperaturas elevadas, o que permite a sua utilização em temperaturas consideravelmente superiores à temperatura máxima de serviço de aços baixa liga ou de aços inoxidáveis martensíticos e ferríticos. Estas características são conseguidas principalmente em aços inoxidáveis austeníticos ligados com Mo ou Si [1]. Neste contexto, salienta-se o desenvolvimento do aço inoxidável austenítico AISI 317L, muito utilizado para confecção de tubos e de revestimentos tipo "clad" empregados nas refinarias, com teor de carbono limitado à $0,03 \%$ e teor de Mo entre 3,00 e 4,00\%, possuindo ainda melhor resistência à

Recebido em 11/03/2014, texto final em 01/09/2014.

DOI: http://dx.doi.org/10.1590/0104-9224/SI1903.05 fluência e melhor resistência à corrosão, quando comparado com outras classes de aços inoxidáveis austeníticos [1]. Apesar das qualidades inerentes ao aço AISI 317L, seu uso na indústria de processo esbarra em problemas metalúrgicos, por mudanças na microestrutura, provocadas por elevadas temperaturas, decorrentes de um aumento significativo da ferrita- $\delta$, o que aumenta a suscetibilidade à corrosão intergranular, aliado à decomposição de fases intermetálicas, tais como as fases $\sigma$ e $\chi$, o que acarreta em degradação das propriedades deste material, principalmente em juntas soldadas expostas a elevadas temperaturas de serviço [2-3].

A fase $\sigma$ é uma das fases intermetálicas mais estudadas, no que tange à degradação dos aços inoxidáveis. $\mathrm{O}$ enriquecimento local de cromo na ferrita $\delta$ em condições de aquecimento, resfriamento e/ou solidificação são os principais fenômenos que favorecem à precipitação da fase $\sigma$ nos aços inoxidáveis austeníticos [4]. Padilha et al.[5] destacam que a cinética da precipitação da fase $\sigma$, em aços inoxidáveis com estrutura totalmente austenítica, é muito lenta, sendo necessárias centenas ou milhares de horas, para que ocorra a formação destes precipitados. Os autores apontam que a cinética lenta se deve a três causas: a insolubilidade do carbono e do nitrogênio na fase 


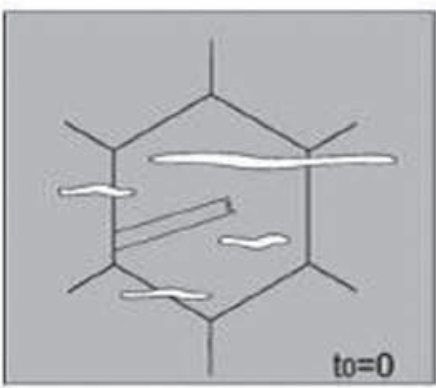

a)

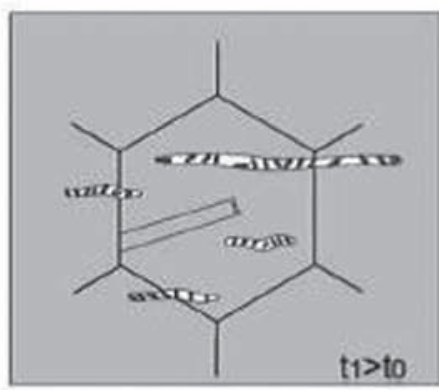

b)

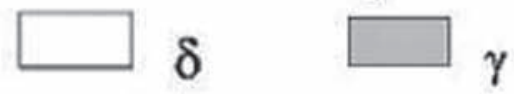

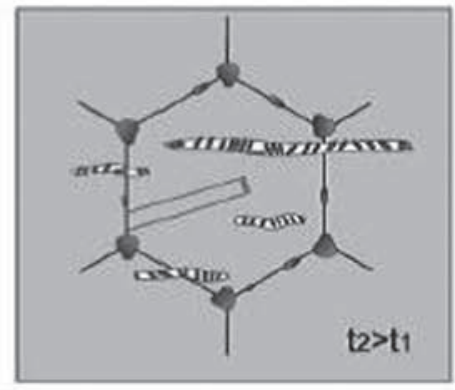

c)

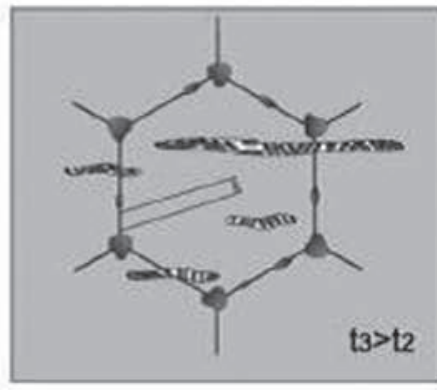

d)

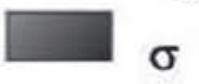

\section{$\gamma_{\text {secundária }}$}

Figura 1. Representação esquemática da precipitação da fase $\sigma$ em um aço inoxidável austenítico contendo ferrita $\delta$ [6].

$\sigma$, acarretando à precipitação desta fase após a precipitação de carbonetos e/ou nitretos; a complexidade da estrutura cristalina da fase $\sigma$, com 30 átomos na célula unitária e o fato de ser formada por elementos de solução sólida substitucional, o que requer longos tempos de difusão.

A precipitação da fase $\sigma$ a partir da ferrita $\delta$ é preferencial e significativamente mais rápida, visto que a difusão do cromo e do molibdênio é cerca de 100 vezes mais rápida na ferrita do que na austenita. A ferrita $\delta$ se decompõe através de uma reação eutetóide do tipo: $\delta \rightarrow \sigma+\gamma$ secundária. Tal fato ocorre porque a ferrita $\delta$ possui uma composição química mais rica em $\mathrm{Cr}$, Mo e $\mathrm{Si}$, elementos facilitadores da formação da fase $\sigma$ [5-6]. A Figura 1 apresenta a representação esquemática da precipitação da fase $\sigma$ em um aço inoxidável austenítico contendo ferrita $\delta$.

A queda da resistência à corrosão, nos aços austeníticos, provocada pela precipitação de fase $\sigma$ se deve a remoção de cromo e molibdênio da matriz austenítica, criando regiões pobres em cromo, susceptíveis à corrosão [5]. Embora tenha se acostumado a chamar de sensitização o fenômeno de empobrecimento de cromo causado pela precipitação intergranular de carbonetos de cromo na faixa de $450^{\circ} \mathrm{C}$ a $850^{\circ} \mathrm{C}$, deixando regiões pobres em cromo vizinhas aos contornos de grão austeníticos, a precipitação de fase $\sigma$ causa efeito semelhante e também pode ser chamada de sensitização. Neste último caso, entretanto, a corrosão resultante da sensitização do aço não necessariamente será intergranular, podendo ser localizada dentro ou nas adjacências da ferrita $\delta$ em decomposição. Simultaneamente, o aço pode ser sensitizado pela precipitação intergranular de carbonetos de cromo. Tomando como exemplo o aço AISI $310 \mathrm{~S}$, de alto $\mathrm{Cr}$, a precipitação de carbonetos de cromo a partir da austenita precede e é substituída pela formação de fase $\sigma\left(\gamma \rightarrow \sigma+\gamma_{2}\right)$ [7].

Visto que há potenciais aplicações em tubos experimentando temperaturas acima de $500^{\circ} \mathrm{C}$, em fornos nas refinarias [3], é importante investigar se tais condições de serviço podem provocar alterações microestruturais e de propriedades no material AISI 317L, ampliando assim o embasamento científico, para uma melhor previsão do seu comportamento mecânico e evolução microestutural para aplicações em alta temperatura, uma vez que há poucos dados na literatura.

\section{Materiais e Métodos}

\subsection{Materiais}

\subsubsection{Material de Base}

A junta soldada foi efetuada utilizando-se como material de base chapas de aço AISI 317L, com dimensões 296 mm x

Tabela 1. Composição química do metal base conforme dados do fabricante ( $\%$ em peso)

\begin{tabular}{c|c|c|c|c|c|c|c|c|c|c|c|c}
\hline Material & C & Mn & Si & S & P & Cr & Ni & Mo & Cu & Ti & Nb & Co \\
\hline AISI 317L & 0,024 & 1,34 & 0,47 & 0,003 & 0,031 & 18,13 & 11,41 & 3,02 & 0,04 & 0,003 & 0,016 & 0,13 \\
\hline
\end{tabular}

Tabela 2. Composição química da vareta GTAW conforme certificação do fabricante (\% em peso)

\begin{tabular}{c|c|c|c|c|c|c|c|c|c} 
Consumível & C & Mn & Si & S & P & Cr & Ni & Mo & Cu \\
\hline AWS A 5.9 ER 317L & 0,008 & 1,75 & 0,56 & 0,002 & 0,024 & 19,1 & 14,1 & 3,19 & 0,11 \\
\hline
\end{tabular}

Tabela 3. Parâmetros de soldagem utilizados e energia de soldagem média.

\begin{tabular}{c|c|c|c|c|c|c}
\hline Processo & $\boldsymbol{\Phi ( \mathbf { m m } )}$ & Polaridade & Corrente (A) & Tensão (V) & $\mathbf{E}_{\mathbf{s}}(\mathbf{k J} / \mathbf{m m})$ & $\mathbf{N}^{\mathbf{0}}$ Passes \\
\hline GTAW & 2,4 & CC- & $112-150$ & $9-10$ & $0,9-1,0$ & 7 \\
\hline \multicolumn{7}{|c|}{$\phi-$ diâmetro da vareta de soldagem; $E_{S}-$ energia de soldagem }
\end{tabular}


$116 \mathrm{~mm} \times 8,5 \mathrm{~mm}$. A Tabela 1 exibe a composição química do aço inoxidável estudado, conforme dados do fabricante.

\subsubsection{Material de Adição}

Como material de adição na soldagem GTAW foi utilizada a vareta do tipo AWS A 5.9 ER $317 \mathrm{~L}$, com diâmetro $(\phi) 2,4 \mathrm{~mm}$. A Tabela 2 apresenta a composição química da vareta, conforme análise química certificada pelo fabricante.

\subsection{Procedimento de Soldagem}

A soldagem foi realizada pelo processo GTAW, com soldador qualificado. As juntas foram preparadas em chapas de $8,5 \mathrm{~mm}$ de espessura, com chanfro em V, com ângulo de bisel de $37,5^{\circ} \mathrm{e}$ abertura de raiz de 4,0 mm, conforme apresentado na Figura 2.

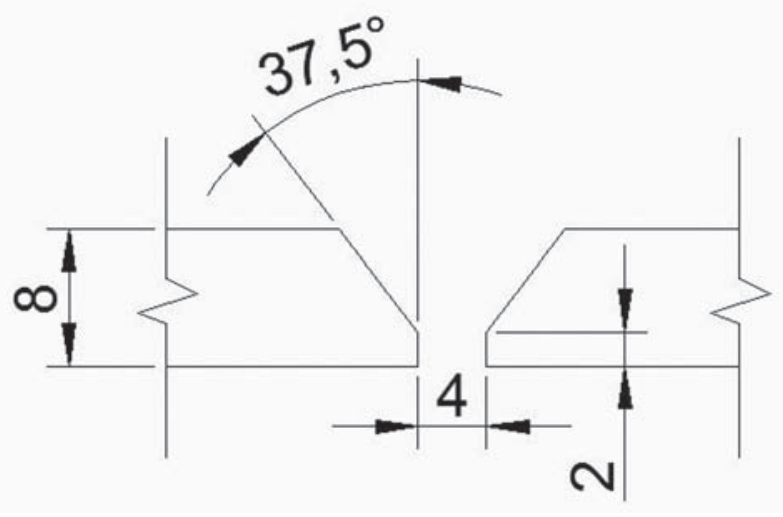

Figura 2. Detalhes da geometria da junta soldada. Medidas em $\mathrm{mm}$.

A soldagem multipasses foi realizada na posição plana, com temperatura interpasse de $150^{\circ} \mathrm{C}$, utilizando como gás de proteção o Argônio com 99,99\% de pureza. Os parâmetros de soldagem foram medidos com multímetro aferido, nos terminais da fonte de energia, e são apresentados na Tabela 3. A velocidade de soldagem foi medida com auxílio de um cronômetro. A energia de soldagem $\left(E_{s}\right)$ não variou significativamente nos 7 passes realizados, situando-se na faixa indicada na Tabela 3.

\subsection{Análise Química}

Foi realizada análise química por espectrometria de emissão óptica por centelha, em corpo-de-prova extraído do metal de solda, objetivando determinar os teores dos principais elementos presentes.

\subsection{Tratamento Térmico para Caracterização de Fases Deletérias}

Após a soldagem, foi realizado o envelhecimento de três amostras de junta soldada, em um forno tipo mufla, na temperatura de $550^{\circ} \mathrm{C}$ por 200 horas, 300 horas e 400 horas, com posterior resfriamento em água. Vale ressaltar que estas condições foram comparadas à condição da junta como soldada, ou seja, sem tratamento de envelhecimento. Os envelhecimentos foram realizados a $550^{\circ} \mathrm{C}$ porque esta temperatura pode ser atingida em algumas aplicações do aço AISI 317L.

\subsection{Análise Microestrutural}

Como método de análise microestrutural utilizou-se a microscopia eletrônica de varredura (SEM) obtendo-se imagens por elétrons retroespalhados $(B S E)$. Foram realizadas microanálises por espectroscopia de energia dispersiva de raios-X $(E D S)$. A preparação das amostras consistiu no lixamento e posterior polimento com pasta de diamante, sem utilização de ataque químico posterior. Nestas condições foram avaliadas as microestruturas do metal de solda, nas condições de como soldado e envelhecidas. O teor de ferrita delta na junta soldada foi medido utilizando um Ferritoscópio Helmut Fisher.

\subsection{Ensaio de Corrosão}

Para avaliação da susceptibilidade do material à corrosão intergranular, ou seja, o seu grau de sensitização, foram realizados testes de polarização eletroquímica de reativação cíclica (PERC ou " $D L-E P R$ "), utilizando um potenciostato conectado a uma célula contendo três eletrodos (eletrodo de trabalho, eletrodo de referência (SCE), contra eletrodo), conforme a norma ASTM G108 [8].

Nos ensaios de DL-EPR foi utilizada uma solução aquosa contendo $2 \mathrm{M} \mathrm{H}_{2} \mathrm{SO}_{4}+0,1 \mathrm{M} \mathrm{KSCN}$, que vem a ser mais agressiva do que a solução padrão para aços AISI 304 e 304L. Os eletrodos de trabalho foram lixados até lixa de granulometria 400. As laterais e vértices do corpo de prova foram cuidadosamente recobertas com esmalte incolor, selecionando sempre uma janela de exposição localizada nos passes de enchimento, ou seja, no centro do cordão de solda. O ensaio foi realizado à temperatura ambiente. A varredura foi iniciada em alguns minutos após a estabilização do potencial de circuito aberto. Em seguida, o potencial foi aumentando no sentido anódico com uma taxa de $1 \mathrm{mV} / \mathrm{s}$ até atingir $0,3 \mathrm{~V}_{\mathrm{SCE}}$. Atingido este valor, a varredura foi invertida no sentido catódico, até retornar ao valor inicial do potencial de circuito aberto. A perda de resistência à corrosão, devido às regiões empobrecidas em cromo, foi avaliada a partir da relação entre as áreas sob a curva de reativação $\left(A_{r}\right)$ e a curva de ativação $\left(\mathrm{A}_{\mathrm{a}}\right)$, obtidas pelo método matemático de integração, aplicado no programa Origin Pro ${ }^{\circledR}$ - Versão 8, em virtude de que foram observados diferentes picos de ativação e reativação nos ensaios efetuados.

Após os ensaios de corrosão algumas amostras foram observadas em microscópio ótico, sem nenhuma preparação adicional.

\section{Resultados e Discussão}

\subsection{Análise Química e Teor de Ferrita Delta do Metal de Solda}

A Tabela 4 apresenta a composição química do metal de solda. Efetuando-se uma análise comparativa com os valores 
Tabela 4. Composição química do metal de solda (\% em peso).

\begin{tabular}{c|c|c|c|c|c|c|c|c|c|c|c|c}
\hline Processo & $\mathbf{C}$ & $\mathbf{M n}$ & $\mathbf{S i}$ & $\mathbf{S}$ & $\mathbf{P}$ & $\mathbf{C r}$ & $\mathbf{N i}$ & $\mathbf{M o}$ & $\mathbf{C u}$ & $\mathbf{T i}$ & $\mathbf{N b}$ & $\mathbf{C o}$ \\
\hline GTAW & 0,008 & 1,63 & 0,61 & 0,003 & 0,028 & 18,26 & 13,63 & 3,08 & 0,11 & 0,003 & 0,016 & 0,10 \\
\hline
\end{tabular}

apresentados nas Tabelas 1 e 2, percebe-se que não houve diferenças significativas em termos de composição química entre o metal base, o metal de adição (vareta) e o metal de solda, exceto pelo teor de Si ligeiramente maior no metal de solda.

O teor de ferrita delta no metal de solda determinado por

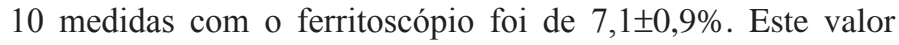
é coincidente com o previsto pelo diagrama WRC-1992 [9], considerando-se os teores de $\mathrm{Cr}_{\text {eq }}(21,3 \%)$ e e $\mathrm{Ni}_{\text {eq }}(13,9 \%)$ do metal de solda.

\subsection{Análise Metalográfica}

As Figuras 3, 4, 5 e 6 apresentam as microestruturas observadas em amostras do metal de solda, por microscopia eletrônica de varredura, no modo de elétrons retroespalhados (BSE), sem ataque, nas condições como soldado e envelhecido à $200 \mathrm{~h}, 300 \mathrm{~h}$ e $400 \mathrm{~h}$, respectivamente.

As Tabelas 5, 6 e 7 mostram a composição química, obtida de forma qualitativa por micro-análise, através de $E D S$, dos pontos de referência indicados nas Figuras.

Observa-se, já na condição de como soldado, as fases ferrita $(\delta)$ e austenita $(\gamma)$ (pontos 1 e 2), onde a microestrutura revela a possível formação de fases intermetálicas (FI) tanto na interface $\delta / \gamma$, como no interior da ferrita $\delta$ (pontos 3 e 4). A análise por $E D S$, apresentada na Tabela 5, revela que as regiões correspondentes aos pontos 3 e 4 possuem mais altos teores de Mo em relação a matriz $\gamma$. As fases ferrita e austenita, como esperado, apresentam composições bem diferentes, com a maior concentração de Ni na austenita e maiores teores de Cr e Mo na ferrita.

No metal de solda envelhecido por 200h, observa-se um aumento da precipitação de fases intermetálicas (FI) no interior da ferrita $\delta$ (ponto 3 ) e bem como a presença da fase massiva na interface $\delta / \gamma$ (ponto 4). As análises do metal de solda envelhecido por 300h mostram uma maior concentração de fases intermetálicas (FI) no interior da ferrita $\delta$, indicando a possível existência de regiões diferenciadas, por apresentarem maiores teores de $\mathrm{Cr}$ e Mo (pontos 3 e 4), em relação aos resultados encontrados na amostra envelhecida por 200h. Finalmente, a microestrutura observada no metal de solda envelhecido por 400h denota um maior crescimento e/ou evolução das fases intermetálicas $(\mathrm{FI})$ na ferrita $\delta$, se comparado ao resultado apresentado na amostra envelhecida por 300h. Os precipitados massivos observados na amostra como soldado (Figura 3) e na amostra envelhecida por $200 \mathrm{~h}$ (Figura 4) não foram observados nas amostras envelhecidas por 300 h (Figura 5) e 400 h (Figura 6), indicando que pode ter havido decomposição dos mesmos.

Devido às pequenas dimensões das fases intermetálicas presentes, considera-se os resultados obtidos por EDS como qualitativos. No entanto, pode ser estabelecido que as imagens com tonalidades mais claras, obtidas por elétrons retroespalhados
(BSE), indicam a presença de fases com altos teores de Mo. Sendo que, quanto mais clara estiver a região em análise, maior será a quantidade de Mo contido na mesma, devido ao seu maior número atômico em relação aos outros elementos $(\mathrm{Cr}, \mathrm{Ni})$. Portanto, acredita-se que as fases encontradas possam corresponder tanto a chi $(\chi)$, sigma $(\sigma)$ ou Laves $\left(\mathrm{Fe}_{2} \mathrm{Mo}\right)$, podendo até coexistirem na ferrita $\delta$ após os tratamentos efetuados [10-11]. Entretanto, a precipitação de qualquer uma destas fases resultará em um forte efeito deletério na junta, em termos de tenacidade e resistência à corrosão. Os precipitados mais finos observados nas Figuras 4, 5 e 6 têm tamanhos e morfologias similares à fase Laves reportada por Padilha [4].

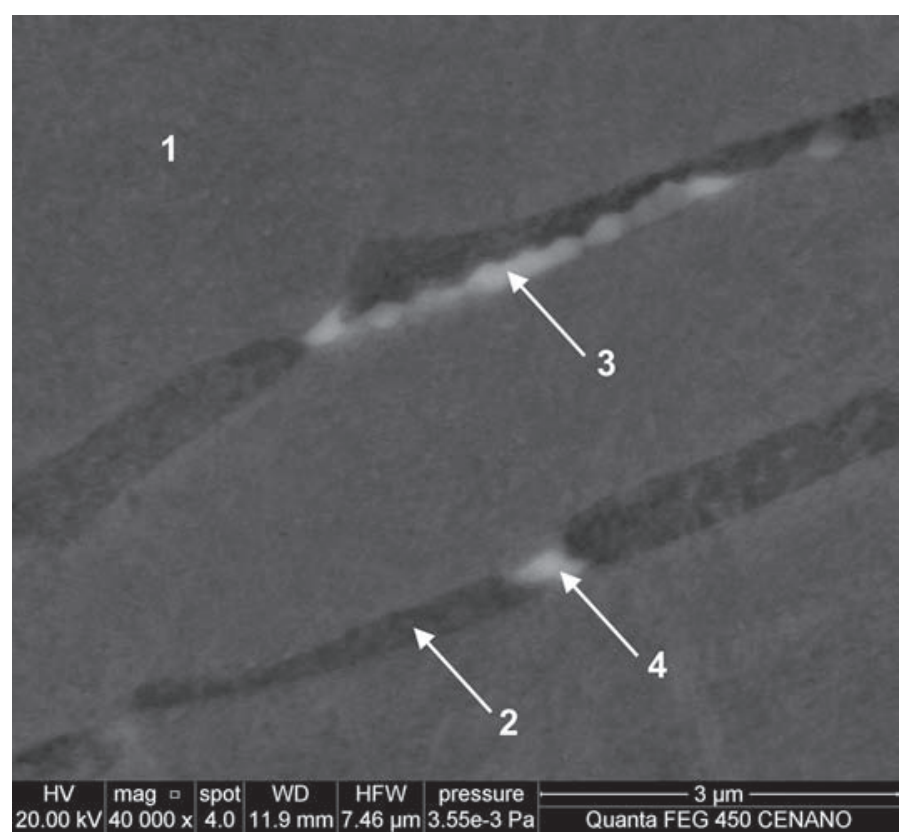

Figura 3. Aspecto microestrutural da condição como soldada observada por microscopia eletrônica de varredura. Aumento: 40000X. Sem ataque.

Tabela 5. Composição química das fases identificadas por EDS na Figura 3 (\% em peso)

\begin{tabular}{c|c|c|c|c|c|c}
\hline Pontos & $\mathbf{F e}$ & $\mathbf{C r}$ & $\mathbf{N i}$ & $\mathbf{M o}$ & $\mathbf{S i}$ & Fase \\
\hline $\mathbf{1}$ & 65,25 & 20,00 & 10,37 & 2,68 & 0,34 & $\gamma$ \\
\hline $\mathbf{2}$ & 63,25 & 24,54 & 6,33 & 4,30 & 0,39 & $\delta$ \\
\hline $\mathbf{3}$ & 60,12 & 24,60 & 5,78 & 7,60 & 0,39 & FI \\
\hline $\mathbf{4}$ & 59,98 & 24,25 & 6,32 & 7,64 & 0,44 & FI \\
\hline
\end{tabular}




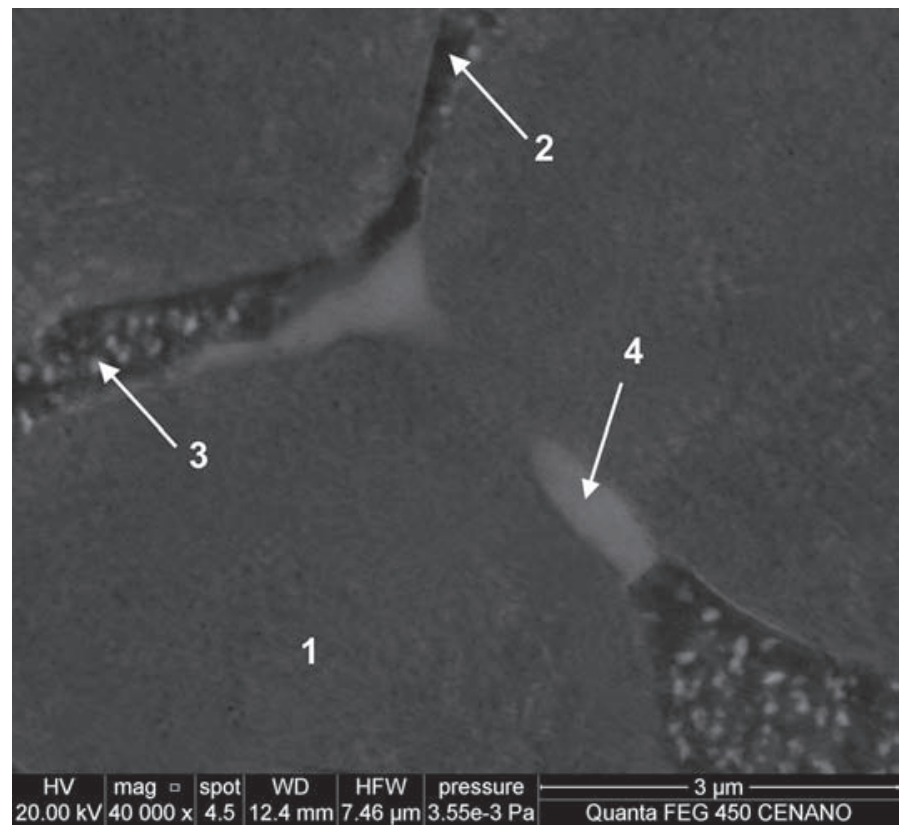

Figura 4. Aspecto microestrutural da condição de envelhecimento por $200 \mathrm{~h}$ observada por microscopia eletrônica de varredura. Aumento: 40000X. Sem ataque.

Tabela 6. Composição química das fases identificadas por EDS na Figura 4 (\% em peso)

\begin{tabular}{c|c|c|c|c|c|c}
\hline Pontos & Fe & Cr & Ni & Mo & Si & Fase \\
\hline $\mathbf{1}$ & 62,57 & 20,87 & 12,07 & 2,57 & 0,26 & $\gamma$ \\
\hline $\mathbf{2}$ & 61,95 & 24,19 & 8,47 & 3,72 & 0,43 & $\delta$ \\
\hline $\mathbf{3}$ & 57,86 & 27,05 & 6,09 & 6,26 & 0,52 & FI \\
\hline $\mathbf{4}$ & 59,56 & 24,54 & 9,02 & 4,86 & 0,35 & FI \\
\hline
\end{tabular}

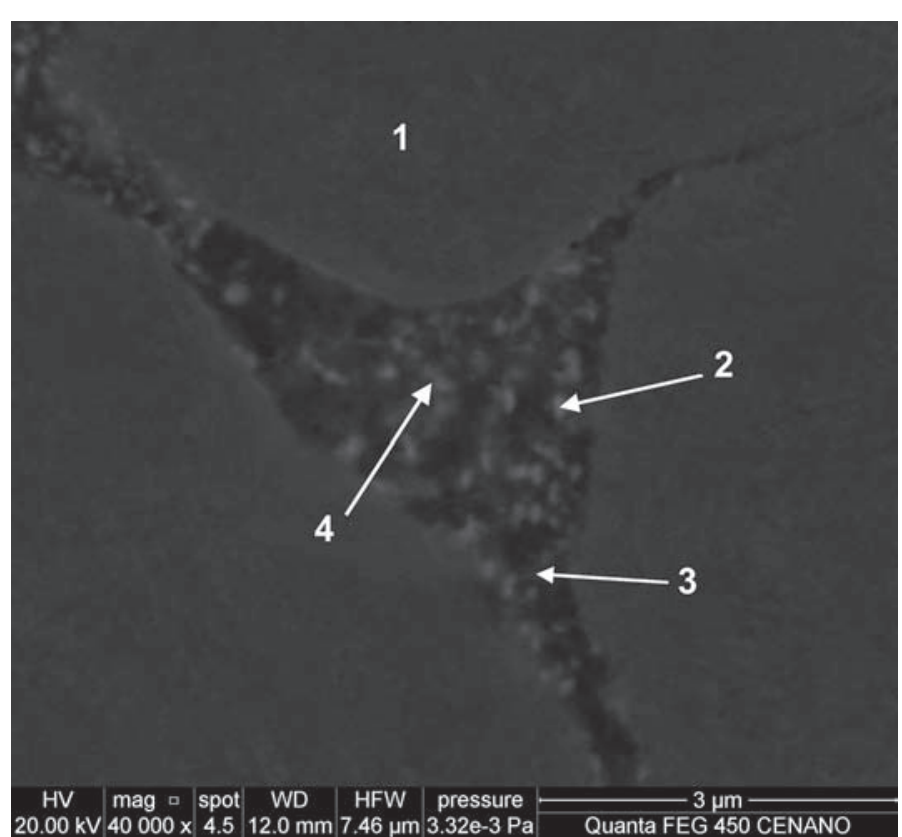

Figura 5. Aspecto microestrutural da condição de envelhecimento por $300 \mathrm{~h}$ observada por microscopia eletrônica de varredura. Aumento: 40000X. Sem ataque.
Tabela 7. Composição química das fases identificadas por EDS na Figura 5 (\% em peso)

\begin{tabular}{c|c|c|c|c|c|c}
\hline Pontos & Fe & Cr & Ni & Mo & Si & Fase \\
\hline $\mathbf{1}$ & 63,84 & 20,37 & 11,76 & 2,31 & 0,32 & $\gamma$ \\
\hline $\mathbf{2}$ & 60,00 & 26,92 & 5,21 & 6,07 & 0,53 & FI \\
\hline $\mathbf{3}$ & 59,32 & 27,93 & 4,31 & 6,60 & 0,59 & FI \\
\hline $\mathbf{4}$ & 59,13 & 27,92 & 4,80 & 6,63 & 0,54 & FI \\
\hline
\end{tabular}

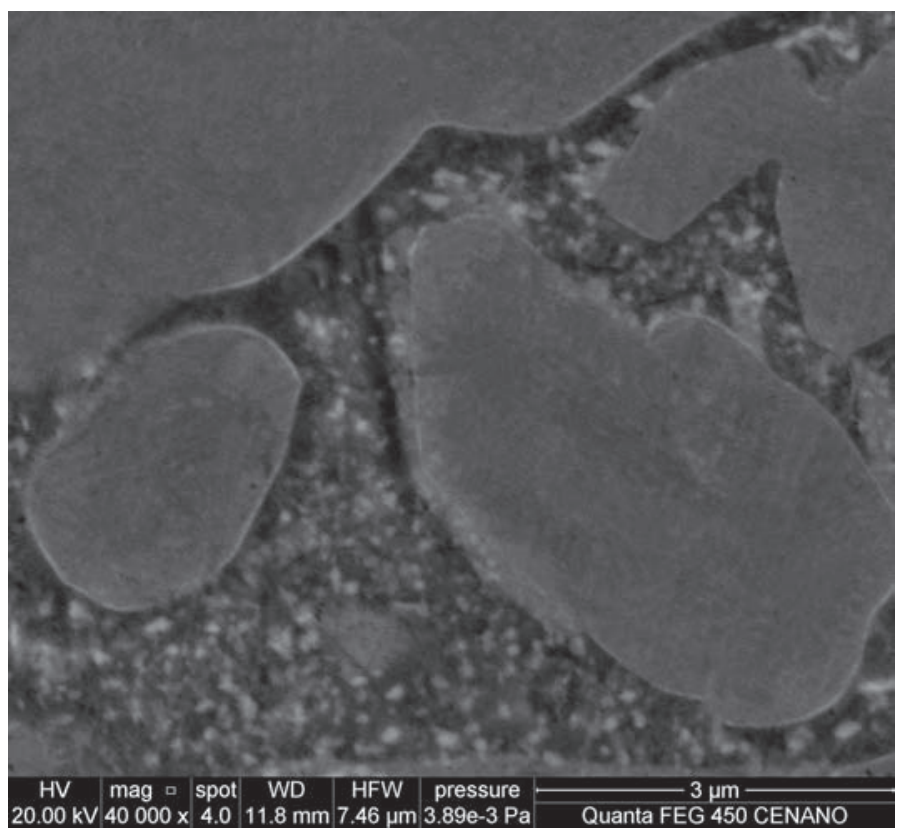

Figura 6. Aspecto microestrutural da condição de envelhecimento por $400 \mathrm{~h}$ observada por microscopia eletrônica de varredura. Aumento: 40000X. Sem ataque.

\subsection{Ensaios de Corrosão}

As Figuras 7(a-d) apresentam as curvas obtidas no ensaio PERC (DL-EPR), onde observa-se o surgimento de picos de reativação nas amostras envelhecidas. Uma análise mais detalhada, apresentada na figura $7(\mathrm{~d})$, revela que surgem dois picos de reativação, provavelmente devido a duas fases deletérias. Por isso, torna-se mais conveniente expressar o grau de sensitização na forma da relação de áreas, e não como a relação entre as correntes de pico $\left(\mathrm{I}_{\mathrm{r}} / \mathrm{I}_{\mathrm{a}}\right)$, como é comumente feito em outros trabalhos $[7,12]$.

A Figura 8 mostra o gráfico da variação do grau de sensitização para cada uma das condições avaliadas, indicando um pequeno grau de sensitização no metal de solda, na condição como soldada. De fato, a análise da microestrutura, nesta condição, já indicou a precipitação de fases intermetálicas (Figura 3). Com o progresso do envelhecimento o grau de sensitização aumenta, indicando que há uma maior quantidade de fases precipitadas.

A observação dos corpos de prova em microscópio ótico após o ensaio de PERC ( $D L-E P R)$ mostra claramente que, ao contrário do material como soldado (Figura 9(a)), o material envelhecido sofre ataque preferencial na região da ferrita $\delta$, que se encontra em decomposição (Figura 9(b)). 

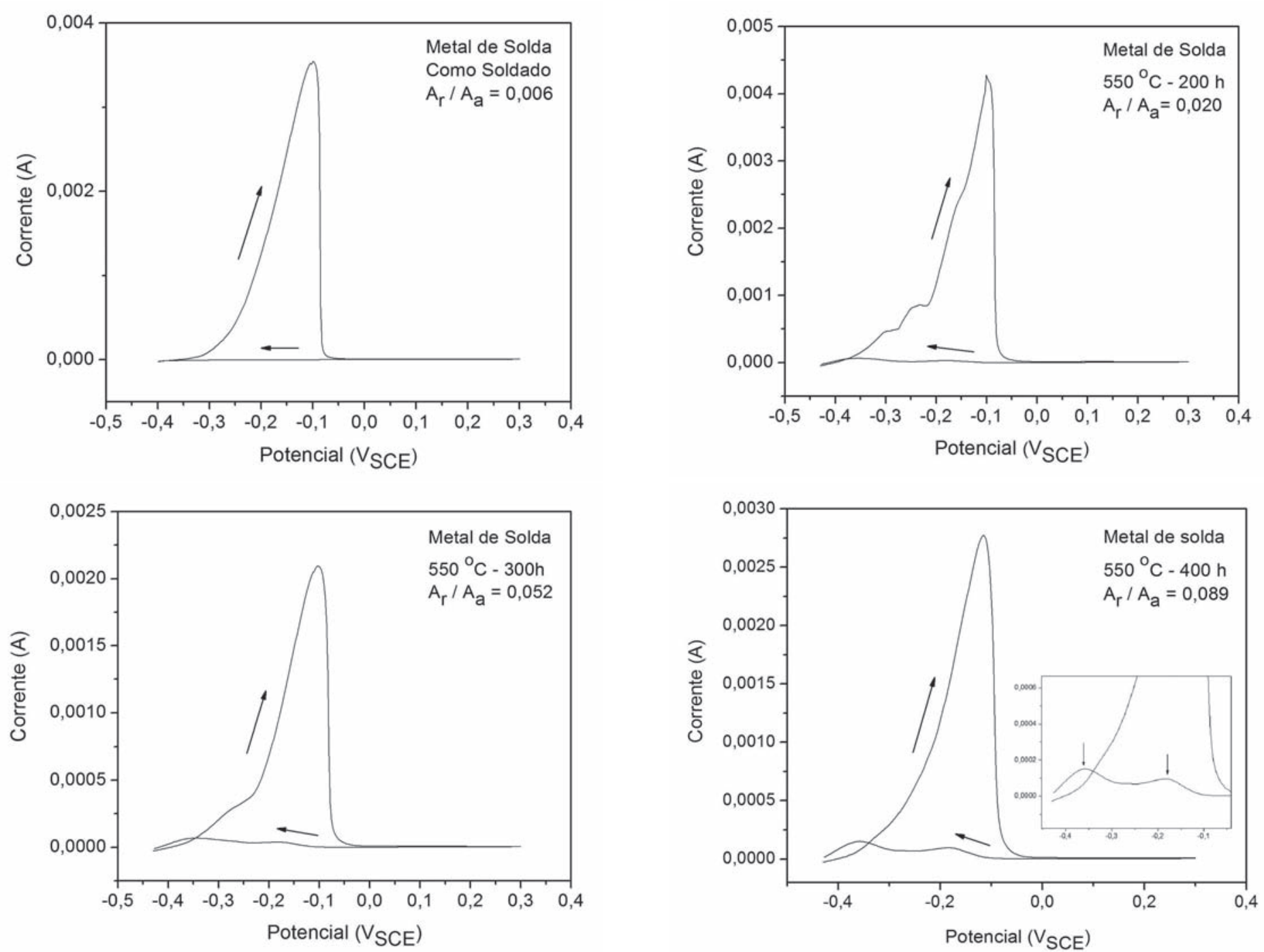

Figura 7. Ensaio DL-EPR nas condições: (a) como soldado; (b) envelhecida a $550^{\circ} \mathrm{C}$ por $200 \mathrm{~h}$ (c) $300 \mathrm{~h}$ e (d) $400 \mathrm{~h}$.

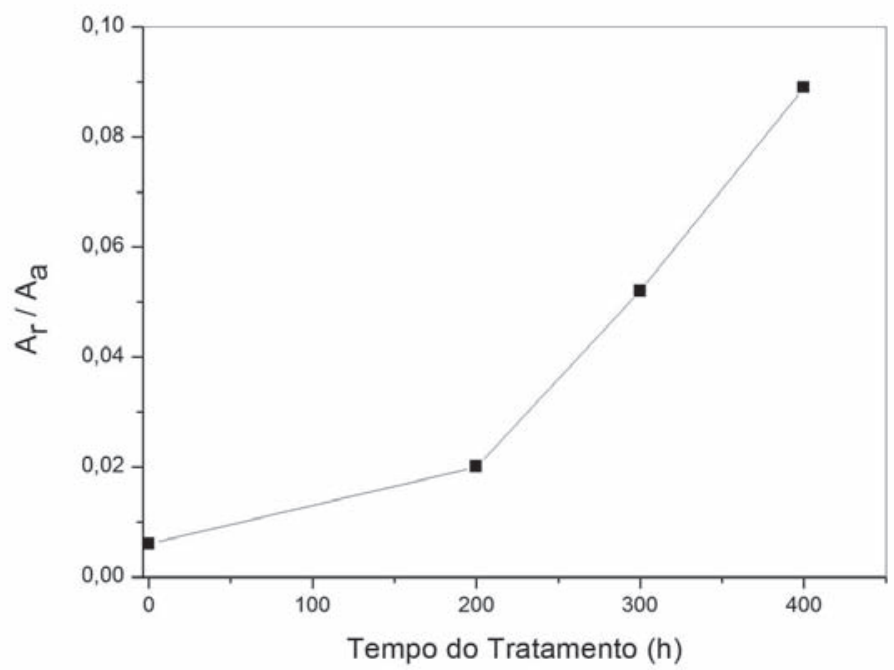

Figura 8. Avaliação do grau de sensitização $\left(\mathrm{A}_{\mathrm{r}} / \mathrm{A}_{\mathrm{a}}\right)$ do metal de solda na condição como soldada e submetido às diversas condições de envelhecimento. 


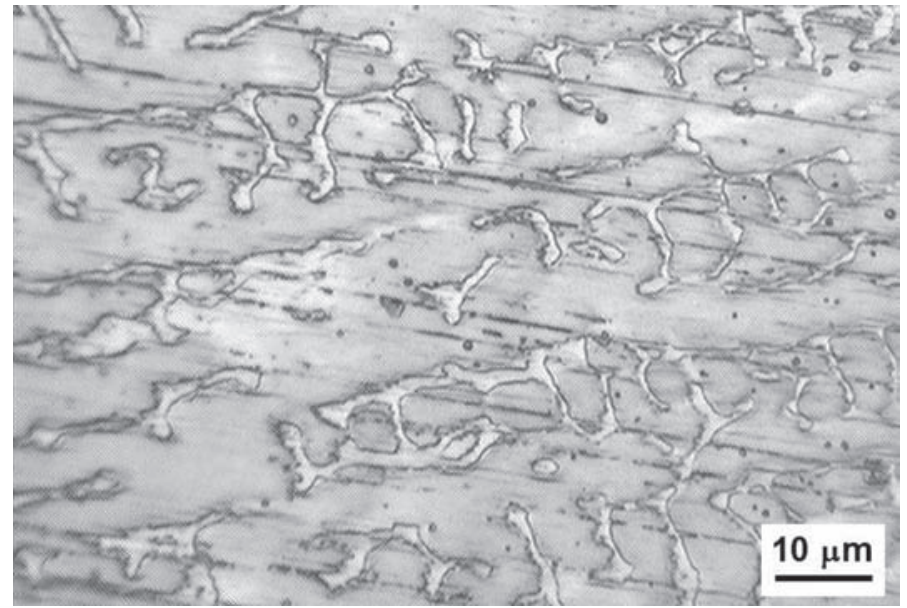

(a)

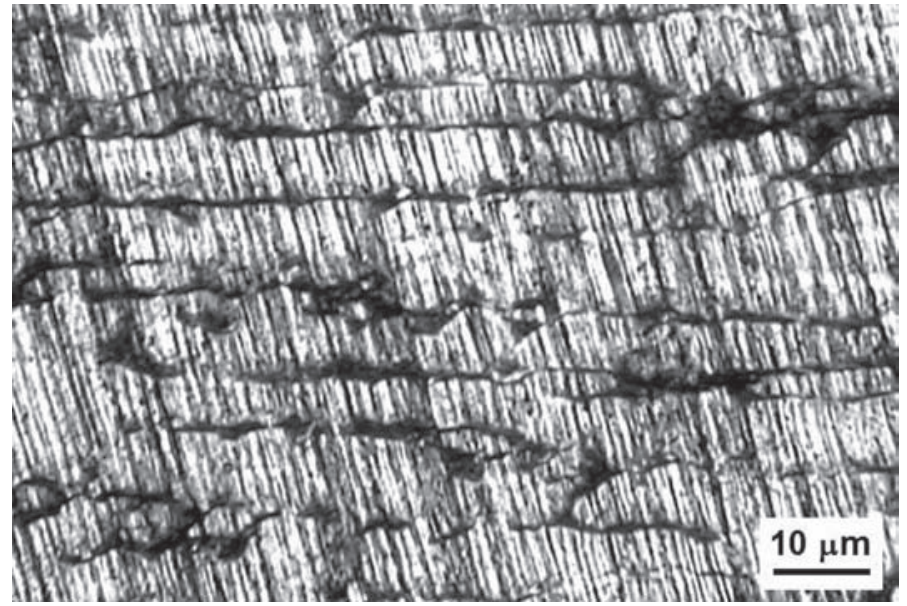

(b)

Figura 9. Micrografias dos corpos de prova após o ensaio de PERC (DL-EPR): (a) como soldado; (b) $550^{\circ} \mathrm{C} / 200 \mathrm{~h}$.

\section{Conclusões}

O presente estudo, que teve como objetivo caracterizar o metal de solda resultante da soldagem GTAW de aço inoxidável AISI 317L, bem como avaliar o efeito do envelhecimento a $550^{\circ} \mathrm{C}$ por tempos de até 400 horas, revelou que:

- O metal de solda, sem envelhecimento, conteve austenita, ferrita delta e traços de fase intermetálica $(\chi$ ou $\sigma$ ) precipitada na ferrita $\delta$.

- Os envelhecimentos a $550^{\circ} \mathrm{C}$ provocaram o aumento progressivo da precipitação de fases, podendo corresponder tanto a chi $(\chi)$, sigma $(\sigma)$ ou Laves $\left(\mathrm{Fe}_{2} \mathrm{Mo}\right)$. Os precipitados claros mais finos, pareceram semelhantes à fase Laves $\left(\mathrm{Fe}_{2} \mathrm{Mo}\right)$.

- Os ensaios de $D L-E P R$ das amostras envelhecidas evidenciaram a presença de dois picos de reativação, que poderiam estar correlacionados com as diferentes fases intermetálicas que se formam no metal de solda.

- O grau de sensitização medido pela relação de áreas dos picos de reativação e ativação $\left(\mathrm{A}_{\mathrm{r}} / \mathrm{A}_{\mathrm{a}}\right)$ aumentou com o aumento do tempo de envelhecimento a $550^{\circ} \mathrm{C}$.

- Após o ensaio de DL-EPR das amostras envelhecidas observouse $o$ ataque preferencial da ferrita em decomposição.

\section{Agradecimentos}

Os autores agradecem às Instituições pelo apoio prestado na execução do presente trabalho: Ao INT - Instituto Nacional de Tecnologia pelo suporte experimental; a CAPES, CNPq pelo apoio financeiro e a UTC Engenharia pelo apoio na realização das soldagens.

\section{Referências Bibliográficas}

[1] FERREIRA, R. C. Estudo da Formação da Fase Sigma em aços Inoxidáveis Austeníticos: Foco nas ligas 317, 317L e 317LN. 2009. 72p. Dissertação (Mestrado) - PPGEM/UFRS, Porto Alegre, RS.

[2] NAGE, D.; et al. Effect of $0.1 \mathrm{wt} \% \mathrm{~N}$ on the Pitting and SCC
Behavior of AS-Welded and Post Weld Heat Treated Austenitic Stainless Steel Weld, Trans. Indian Inst. Met., v.57, n.2, p. 123132, April. 2004.

[3] ECKSTEIN, C. B. et al. Envelhecimento de Tubos de Aço Inoxidável 317L em Ambiente de Temperatura Elevada. In: $11^{\text {a }}$ Conferência sobre Tecnologia de Equipamentos, Ipojuca, PE, Maio, 2011.

[4] PADILHA, A. F.; GUEDES, L. C. Aços Inoxidáveis Austeníticos: Microestrutura e Propriedades. São Paulo: Hemus, 2004. 170p.

[5] PADILHA, A. F. et al. Precipitation in AISI 316L(N) During Creep Tests at 550 and $600{ }^{\circ} \mathrm{C}$ up to 10 years, Journal Nuclear Materials, n. 362, p. 132-138, 2007.

[6] VILlanUEVA, D. M. E. et al. Comparative Study on Sigma Phase Precipitation of Three Types of Stainless Steels: Austenitic, Superferritic and Duplex, Materials Science and Technology, v. 22, n.9, p.1098-1104, 2006.

[7] TAVARES, S. S. M. et al. Microstructural changes and corrosion resistance of AISI 310S, Materials Characteriazation, n. 60, p. 573-579, 2009.

[8] ASTM INTERNATIONAL. G108 - 94: Standard Test Method for Electrochemical Reactivation (EPR) for Detecting Sensitization of AISI Type 304 and 304L Stainless Steels. EUA, 1994, Reapproved 2010.

[9] J. LIPPOLD, D. KOTECKI. Welding metallurgy of stainless steels, , New Jersey/USA: Willey Interscience, 2005. 357p.

[10] SAHLAOUI, H, SIDHOM, H. Experimental Investigation and Analytical Prediction of $\sigma$-Phase Precipitation in AISI 316L Austenitic Stainless Steel, Metal. And Mater. Trans. A, n.44A, p.3077-3083, 2013.

[11] PARDAL, J.M. et al. Deleterious Phases Precipitation on Superduplex Stainless Steel UNS S32750: Characterization by Light Optical and Scanning Electron Microscopy, Materials Research n.13(3), p.401-407, 2010.

[12] MOURA, V. et al. Investigation of Cracks and Sensitization in an AISI 304L Stainless Steel Exposed to $500-600^{\circ} \mathrm{C}$, Engineering Failure Analysis, n.16, p. 545-551, 2009. 